\title{
Mikro Modüllü Dişli-Mil Sıkı Geçme Bağlantılarında Mil Çapı ve Delik Toleransının Gerilme Dağılımına Etkisi
}

\author{
Tuğçe Tezel ${ }^{1}$ \\ Akdeniz Üniversitesi, Mühendislik Fakültesi, Makine Mühendisliği Bölümü, Antalya, Türkiye (ORCID: 0000-0003-0139-442X)
}

(Bu yayın HORA2019 kongresinde sözlü olarak sunulmuştur.)

(İlk Geliş Tarihi 1 Ağustos 2019 ve Kabul Tarihi 25 Ekim 2019)

(DOI: $10.31590 /$ ejosat.638276)

ATIF/REFERENCE: Tezel, T. (2019). Mikro Modüllü Dişli-Mil Sıkı Geçme Bağlantılarında Mil Çapı ve Delik Toleransının Gerilme Dağılımına Etkisi. Avrupa Bilim ve Teknoloji Dergisi, (Özel Sayı), 330-335.

\section{Öz}

Makine tasarımı ve imalatında yaygın kullanıma sahip makine elemanlarından biri dişliler olup birçok alanda çeşitli boyutlarda dişli kullanımına ihtiyaç duyulmaktadır. Modülü $1 \mathrm{~mm}$ ve daha küçük olan mikro modüllü dişliler ise, hassas ölçüm aletlerinde, savunma sanayinde ve makine imalatında önemli bir makine elemanı olarak kullanılmaktadır. Güç aktarımı sürecinde dişli yüzeyinde, dişte, dişli gövdesinde ve dişli-mil bağlantısında meydana gelen hasarlar, tüm makinenin normal çalışmasını etkilemektedir. Oluşan herhangi bir hasar yalnızca dişli ya da dişli bağlantısını değil, bu elemanla birlikte çalışan birçok makine parçasını da hasara uğratabilir. Mikro modüllü dişlilerin küçük boyutları nedeniyle dişli-mil bağlantısında sıkı geçme bağlantıları ön plana çıkmaktadır. Ancak bu konuda literatürde önemli eksiklikler bulunmaktadır. Tasarımcıların tüm sıkı geçme toleranslarını uygulamalı olarak denemesi hem vakit hem de ekonomik kayıplara yol açabilir. Bu sebeple analitik ve nümerik hesaplamaların, dişli göbeği mil sıkı geçme bağlantılarında önemi büyüktür.

Bu çalışmada, farklı göbek çaplarına sahip 1 mm modül, 6 mm genişlik ve 20 diş sayısına sahip bir mikro modül dişlide; farklı sıkı geçme toleranslarında oluşan gerilme dağılımları sayısal ve analitik olarak hesaplanıp karşılaştırılmıştır. Analitik ve sayısal çalışmadan elde edilen veriler birbiriyle uyum içerisindedir. Nominal çap arttıkça meydana gelen teğetsel ve radyal gerilme azalmaktadır. Ancak bu noktada zayıflayan dişli gövdesi meydana gelebilecek hasarlara açık konumdadır. Çalışmada kullanılan tüm nominal çap değerleri için dişli mil bağlantısından ötürü meydana gelen teğetsel ve radyal gerilme büyüklüğü H7/u6, H7/s6, H7/p6 şeklinde sıralanmaktadır.

Anahtar Kelimeler: mikro modüllü dişli, sıkı geçme, dişli mil bağlantısı.

\section{The Effect of Shaft Diameter and Hole Tolerance on Stress Distribution in Micro Module Gear-Shaft Interference Fitting Connections}

\begin{abstract}
One of the widely used machine elements in machine design and manufacturing is gears, and in many areas, the use of various sizes of gears is needed. Micro module gears with module $1 \mathrm{~mm}$ and smaller are used as an important machine element in precision measuring instruments, defense industry and machine manufacturing. Damage to the gear surface, gear teeth, gear body and gear-shaft connection
\end{abstract}

${ }^{1}$ Sorumlu Yazar: Akdeniz Üniversitesi, Mühendislik Fakültesi, Makine Mühendisliği Bölümü, Antalya, Türkiye, ORCID: 0000-0003-0139-442X, 
during power transmission affect the normal operation of the entire machine. Any damage that may occur can damage not only the gear or gear connection, but also many machine parts that work with this machine elements. Due to the dimensions of the micro-module gears, the interference-fitting connections come into prominence in the gear-shaft connection. However, there are important shortages in the literature. Designers practicing all interference-fitting connections can lead to both time and economic losses. For this reason, the analytical and numerical calculations are of great importance in the gear hub shaft interference fitting connections.

In this study, the stress distributions are calculated and compared numerically and analytically that occur at different interference fit tolerances and different hub diameters for micro module gear having 20 teeth number, $6 \mathrm{~mm}$ width and $1 \mathrm{~mm}$ module. The data obtained from the analytical and numerical studies are in agreement with each other. Axial and radial stress decreases as the nominal diameter increases. At this point, however, the weakened gear surface is vulnerable to damage. For all nominal diameter values used in the study, the axial and radial stress magnitude caused by the gear shaft connection are listed as H7/u6, H7/s6, H7/p6, respectively.

Keywords: micro module gear, interference fitting, gear-shaft connection.

\section{Giriş}

Sıkı geçme bağlantıları, montaj öncesi birbirlerine göre boyut fazlalığı olan delik ve milllerin birleştirilmesiyle oluşturulur. Böylelikle ortak yüzeyde üniform bir bağlantı basıncı oluşarak darbeli torkların ve eksenel kuvvetlerin iletilmesi için bir bağlantı kuvveti üretilir. Sıkı geçme bağlantıları esas olarak hareketsiz bağlantılar için kullanılır. Bu bağlantılar ucuz ve yapılması kolay olduğu için sıklıkla tercih edilmektedir. Buna ek olarak, küçük çaplardaki bağlantılar için uygu kaması vb. bağlantı yöntemlerinin imalatındaki zorluklar sıkı geçme bağlantısının kullanımını ön plana çıkarmaktadır. Ancak oluşturulan basınca bağlı olarak geçiş noktalarında, şaftın soğuk şekillenmesi ve yüzey sertleşmesi nedeniyle yüksek çentik etkisi meydana gelir (yaklaşık \%10 - 20). Bu nedenle özellikle küçük çaplar için yapılan sıkı geçme bağlantılarının hesaplarında dikkatli olunmalıdır [1].

Literatür incelendiğinde çalışmaların mil sıkı geçme bağlantıları etkisiyle küçük boyutlu dişlilerdeki gerilme dağılımından ziyade genel olarak normal boyutlu dişli mil sıkı bağlantıları üzerine yoğunlaştığı görülmektedir. Kovan (2018) çalışmasında, sıkı geçmeden ötürü oluşan gerilmelerin, geleneksel hesaplama yöntemlerini kullanarak tüm koşullar için yapılan hesaplanmalardaki yetersizliğini ortaya koymuştur. Çalışmada elasto-plastik sıkı geçme gerilmelerini hafif metal dişli ve çelik bağlantıları için analitik ve sayısal olarak hesaplamıştır. Deformasyonun azalan çapa bağlı olarak arttığı ve artan sıkı geçme oranları ile sayısal hesaplama yöntemlerinin daha doğru sonuçlar verdiğini belirtmiştir [2]. Kovan (2011) bir diğer çalışmasında çeşitli çaplarda mil ve delikler için, mil-göbek bağlantısında meydana gelen gerilme ve ayrılma frekansını analitik ve sayısal olarak analiz etmiştir [3]. Xiang ve ark. (2017) sıkı geçme bağlantı yüzeylerinin temas özellikleri ile aşınma arasındaki ilişkiyi bir rüzgar türbini planet dişlisinin gerilme analizine dayanarak hesaplamıştır. Bir bağlantı yüzeyinin gerilme değerlerini farklı sıkı geçme koşulları ve dış yüksüz koşullar altında analitik ve nümerik olarak inceleyerek, elde edilen sonuçları karşılaştırmıştır [4]. Pedersen (2016) çalışmasında mil göbek sıkı geçme bağlantısını iyileştirmek için, temas basıncı dağılımını iyileştiren farklı tasarımlar geliştirerek göbek tarafındaki şekil optimizasyonunun basınç dağılımını önemli ölçüde iyileştirebileceğini göstermiştir [5]. Zhou ve ark. (2018) dişli ve mil arasındaki sıkı geçme yüzeyinin gerilmesi ve deformasyonunu inceledikleri çalışmalarında, ara yüz için izin verilen maksimum deformasyon ve temas gerilmesini veren matematiksel bir model geliştirmişlerdir. Sonuçlar, hesaplama ve analiz yöntemlerinin, dişli ve mil arasına uygun sıkı geçmenin talaşlı işlenmesi ve seçilmesi için teorik bir destek sağlayabildiğini göstermektedir [6]. Zhao ve ark. (2016), planet dişli sisteminde, temas analizini nümerik olarak planet dişli ile yatağın dış halkası arasındaki farklı sıkı geçme büyüklükleri sonucu gerilmeleri hesaplamak için kullanmışlardır [7]. Joshi (2018), yaptı̆ğ sonlu elemanlar analizinde sıkı geçme bağlantısı tasarımı ve sıkı geçme sonrası şekilden sapmaları incelemiştir. Dişlilerdeki sıkı geçme montajı nedeniyle diş profilinde oluşan bozulmayı montaj öncesi ve sonrası diş profili ölçümleriyle incelemiştir. Diş profilinde oluşan değişimi hesaplamak için bir algoritma geliştirmiştir [8]. Boutoutaou ve Fontaine (2015) çalışmalarında sıkı geçme bağlantı tekniğinde, bağlantı sağlanmayan parçaların şekli ve yüzey kalitesi ile ilgili kısıtlı varsayımlara dayanan eski modellerin kullanıldığını belirterek sonlu elemanlarla analizinin yapılmasını önermişlerdir [9].

Literatürden anlaşılacağı gibi sıkı geçme bağlantılarının analizi, araştırmacılar tarafından analitik, sayısal ve deneysel olarak yapılmaktadır. Croccolo ve ark. (2011) ve Kim ve Lee (2006) sıkı geçmelerde burç çevresine yerleştirdikleri "strain-gauge" ile birim uzamayı ölçerek temas basıncını tahmin etmeye çalışmışlardır [10-11]. Temas basıncını ve sıkı geçmedeki dağılımını ölçmek için bir başka yöntem de Lewis ve ark. (2005) tarafından ultrasonik ölçümler kullanılarak yapılmıştır [12]. Deneysel çalışmaların tüm sıkı geçme parametreleri için uygulanması ekonomik olmadığından sonlu elemanlar analizinin ve analitik hesaplamaların önemi ortaya çıkmaktadır. Sıkı geçme tasarımında kullanılan analitik hesaplamalardaki modellerin çoğu, elastik aralıktaki iki boyutlu bir gerilme analizine dayanan, Lame ve Clapeyron tarafından kurulan denklemlere dayanmaktadır [13]. Ancak bu denklemlerin yetersizliği de çeşitli çalışmalarla ortaya konmuştur [14-15]. Böylelikle sayısal hesaplamalarla sıkı geçme bağlantılarında meydana gelen gerilmelerin ortaya konmasının önemi ortaya çıkmaktadır. Sayısal yöntemler, sıkı geçmeyle ilgili tüm parametrelerin detaylı bir şekilde incelenmesini, montaj sürecinin tasarımını, bağlantı gerilmelerinin tahminini ve çalışma koşulları altında bağlantının davranışının incelenmesine olanak sağlamaktadır. Bu nedenle farklı durumlarda sıkı geçme bağlantılarının davranışı birçok araştırmacı tarafından incelenmiştir. Sıkı geçme bağlantılarının gerilme analizi için yaygın olarak kullanılan sonlu elemanlar yöntemiyle elde edilen sonuçlarının, geleneksel hesap yöntemlerinden daha doğru sonuçlar verdiği birçok araştırmacı tarafından tespit edilmiştir [16-17-1819-20-21-22]. 
Literatürde yer alan bu çalışmalar, mikro modüllü dişlilere uygun sıkı geçme boyutlarına ait sonuçları içermemektedir. Mikro modüllü dişlilere uygun, standartlar tarafındanda tavsiye edilen çap serileri ve toleranslar için yapılacak bir çalışma mikro modüllü dişlilerin sıkı geçme bağlantı tasarımlarına fayda sağlayacaktır. Bu çalışmanın amacı, tasarımlarda yaygın bir şekilde kullanılmaya başlayan mikro modül dişli ve mil sıkı geçme bağlantısında elastik-plastik sıkı geçme gerilmelerini incelemektir. Ayrıca, bu çalışmanın bir diğer amacı ise, geleneksel yöntemin Lame-Clapeyron denklemi ve sonlu elemanlar yöntemi temelli sonuçları karşılaştırmaktır. Yapılan çalışma ile birlikte bu alanda eksik olan sonuçlar literatüre kazandırılmış olacaktır.

\section{Materyal ve Metot}

Dişli tasarımı ve imalatında olduğu gibi, dişli mil göbek bağlantılarında da kullanılmak üzere tasarımcılara sunulan standartlardan faydalanmak hem zaman açısından hem de ekonomik açıdan fayda sağlayacaktır. Boyut ve toleranslar hakkında tasarım önerilerinde bulunan ASME B4.2'de temel büyüklüklere göre çeşitli tasarım öncelikleri sunulmuştur. Makine imalatında genel olarak birim delik sistemi kullanılmakta olup ASME B4.2'de H7 delik tolerans1 için H7/p6, H7/s6 ve H7/u6 sık1 geçme bağlantıları önerilir [23]. Bunlardan, H7/ p6, yere doğru hizalama gerektiren parçalarda, H7/s6, hafif kesitlerin orta seviye kuvvet aktarımında, H7/u6 yüksek gerilmye maruz kalan parçalarda kuvvet aktarımında kullanılır. Bu çalışmada öncelikle analitik hesaplamalar yapılmış ardından elde edilen sonuçlar nümerik analiz sonuçlarıyla karşıllaştırılmıştır.

Lame ve Clapeyron [13] tarafından geliştirilen sıkı geçme bağlantı denklemleri Timoshenko [24] tarafından daha da ayrıntılı olarak sunulmuştur. Timoshenko'nun yaklaşımına göre geliştirilen sıkı geçme bağlantılarında meydana gelen basınç;

$$
p=\frac{\delta}{\frac{d}{E_{o}}\left(\frac{d_{o}^{2}+d^{2}}{d_{o}^{2}-d^{2}}+v_{o}\right)+\frac{d}{E_{i}}\left(\frac{d^{2}+d_{i}^{2}}{d^{2}-d_{i}^{2}}+v_{i}\right)}
$$

şeklinde ifade edilmektedir. Burada d nominal mil çapı, $\mathrm{d}_{\mathrm{i}}$ mil iç çapı, $\mathrm{d}_{\mathrm{o}}$ göbek dış çapı, E elastisite modülü ve v Poisson oranıdır. "o" ve "i”" alt indisleri sırasıyla dış kısmı (göbek) ve iç kısmı (mil) tanımlar. $\delta$, ise mil dış çapı ile göbek iç çapı arasındaki farktır.

Mil ve göbek malzemesi aynı olduğu takdirde Denklem 1, Denklem 2'deki şekliyle kullanılır.

$$
p=\frac{E \delta}{2 d^{3}} \quad\left(\frac{\left(d_{o}^{2}-d^{2}\right)\left(d^{2}-d_{i}^{2}\right)}{d_{o}^{2}-d_{i}^{2}}\right)
$$

Maksimum ve minimum boşluk değerleri Denklem 3 ve Denklem 4 yardımıyla hesaplanır.

$$
\begin{aligned}
& \delta_{\text {min }}=d_{\text {min }}-D_{\text {maks }} \\
& \delta_{\text {maks }}=d_{\text {maks }}-D_{\text {min }}
\end{aligned}
$$

Mil ve göbek arasında meydana gelen teğetsel gerilme Denklem 5 ve Denklem 6, radyal gerilme ise Denklem 7 ve Denklem 8 aracılığıyla hesaplanır [25].

$$
\begin{gathered}
\sigma_{t, m i l}=-p\left(\frac{d^{2}+d_{i}^{2}}{d^{2}-d_{i}^{2}}\right) \\
\sigma_{t, g \text { öbek }}=p\left(\frac{d_{o}^{2}+d^{2}}{d_{o}^{2}-d^{2}}\right) \\
\sigma_{r, m i l}=-p \\
\sigma_{r, \text { öbek }}=p
\end{gathered}
$$

Analitik ve nümerik olarak H7/p6, H7/s6 ve H7/u6 sıkı geçme bağlantıları için yapılan bu çalışmada dişli ve mil malzemesi AISI 4340 olarak belirlenmiştir. AISI 4340'a ilişkin çalışmada kullanılan veriler Tablo 1'de yer almaktadır.

Tablo 1. AISI 4340 özellikleri

\begin{tabular}{l|c}
\hline$E(\mathrm{MPa})$ & 199947,96 \\
\hline$E_{t}(\mathrm{MPa})$ & 28957,98 \\
\hline$F_{t y}(\mathrm{MPa})$ & 1496,16 \\
\hline$\alpha(1 / \mathrm{K})$ & 0,00001179 \\
\hline$\mu$ & 0,32 \\
\hline$\omega\left(\mathrm{kg} / \mathrm{m}^{3}\right)$ & 7833,41 \\
\hline$F_{t u}(\mathrm{MPa})$ & 1792,63 \\
\hline
\end{tabular}

Modülü $1 \mathrm{~mm}$, diş sayısı 20 olan, 6 mm genişliğindeki dişlinin göbek çapı 2, 2,5, 3, 4, 5, 6, 8 ve 10 mm olarak H7/p6, H7/s6 ve H7/u6 sıkı geçme bağlantıları kullanılarak dişlide meydana gelen gerilme analitik ve nümerik olarak hesaplanmıştır. Nümerik analiz için sonlu elemanlar analizinden faydalanılmıştır.

\section{Araştırma Sonuçları ve Tartışma}


Analitik hesaplamalar nominal çapa bağlı olarak tekrarlanmak suretiyle H7/p6, H7/s6 ve H7/u6 sıkı geçme bağlantılarında dişlide meydana gelen teğetsel ve radyal gerilme değerleri elde edilmiş olup Şekil 1'de görülmektedir. Tüm nominal çap değerleri için, çap arttıkça meydana gelen teğetsel ve radyal gerilme azalmaktadır. Gerilme verileri birbiriyle uyumlu şekilde büyükten küçüğe doğru, H7/u6, H7/s6, H7/p6 şeklinde sıralanmaktadır. Bir başka deyişle mil çapıyla göbek çapı arasındaki fark büyüdükçe hem teğetsel hem radyal gerilme artmaktadır.

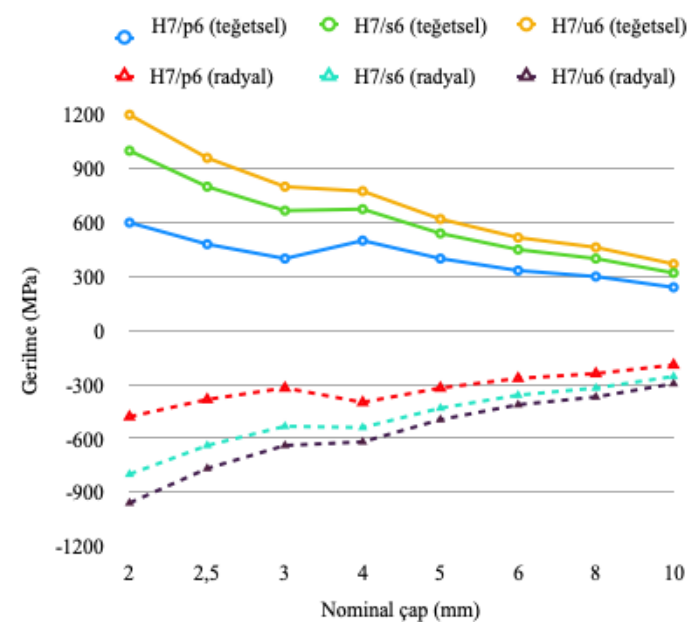

Şekil 1. Nominal çapa bağlı olarak radyal ve teğetsel gerilme değişimi

Şekil 1'de analitik olarak elde edilen hesaplamalar nümerik analizde tekrarlanmıştır. Ø5 için oluşturulan sıkı geçme bağlantılarının nümerik analizlerinden elde edilen teğetsel gerilme sonuçları Şekil 2'de yer almaktadır.

Ø5 H7/u6 teğetsel gerilme sonuçları incelendiğinde meydana gelen en büyük teğetsel gerilme $684 \mathrm{MPa}, \varnothing 5 \mathrm{H7} / \mathrm{s} 6$ 'da meydana gelen en büyük teğetsel gerilme $596 \mathrm{MPa}$ ve Ø5 H7/p6'da meydana gelen en büyük teğetsel gerilme $443 \mathrm{MPa}$ 'dır. Analitik hesaplardan elde edilen veriler ise, Ø5 H7/u6 için 619,8 MPa, Ø5 H7/s6 için 539,9 MPa, Ø5 H7/p6 için 399,9 MPa'dır. Bu sonuçlar doğrultusunda nümerik analizden elde edilen sonuçların analitik çözümleye oldukça yakın sonuçlar verdiği görülmektedir. Ayrıca Şekil 1'e benzer şekilde sıklık arttıkça meydana gelen teğetsel gerilmedeki artış nümerik analizde de ortaya konmuştur.

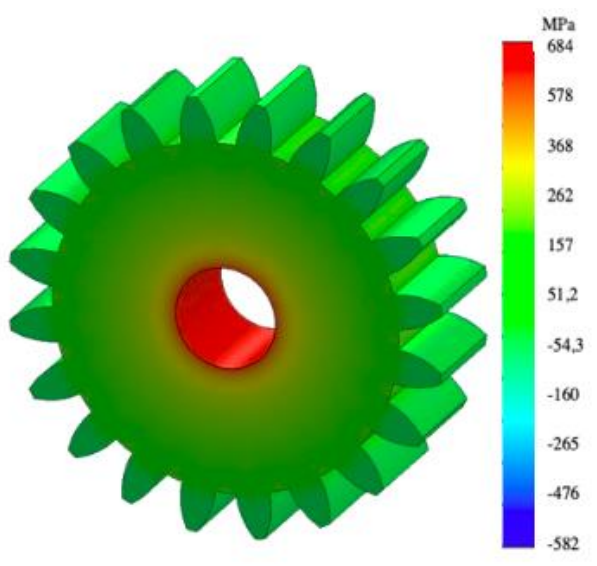

a. $\varnothing 5 \mathrm{H} 7 / \mathrm{u} 6$

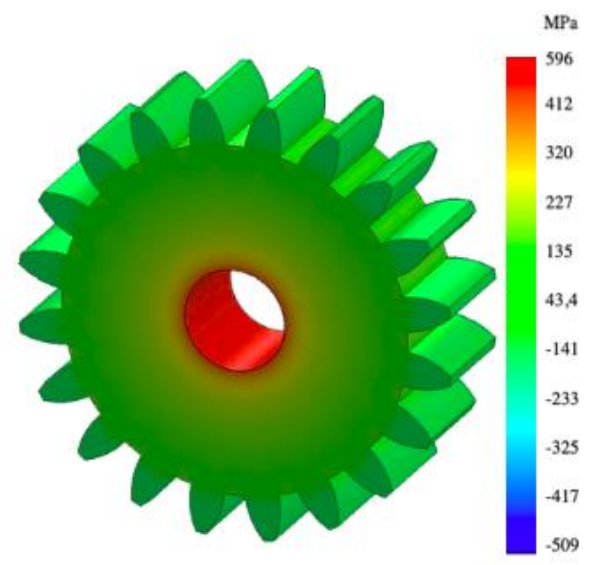

b. $\varnothing 5 \mathrm{H} 7 / \mathrm{s} 6$

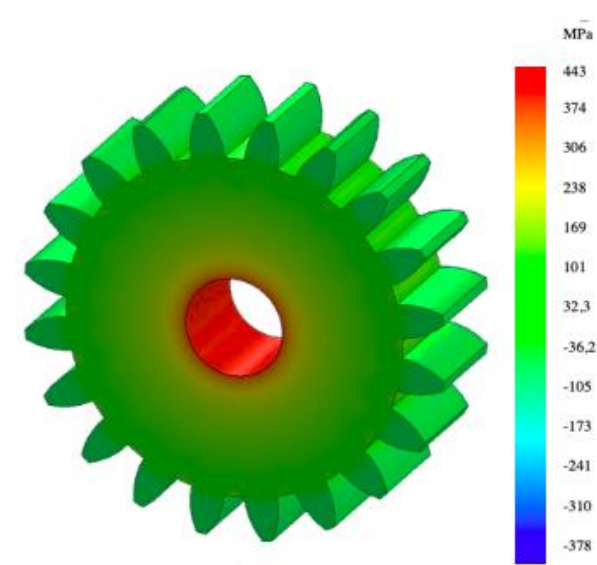

c. $\varnothing 5 \mathrm{H} 7 / \mathrm{p} 6$

Şekil 2. Ø5 sıkı geçme bağlantılarında oluşan teğetsel gerilme

En büyük teğetsel gerilmenin meydana geldiği H7/u6 mil göbek bağlantısında artan nominal çapın dişlide meydana gelen teğetsel gerilmeye etkisi Şekil 3'te incelenmiştir. Mil göbek bağlantısında meydana gelen teğetsel gerilme nominal çap arttıkça azalmaktadır. Ancak bu noktada dişler ve dişler arasında meydana gelen bölgeler de dikkate alınmalıdır. Artan nominal çapla zayıflayan dişli gövdesinde meydana gelen gerilme dişlere ve dişliler arasına da etki etmektedir. H7/u6 dişli mil sıkı geçme bağlantısında farklı nominal çaplar için nümerik ve analitik hesaplamalardan elde edilen sonuçlar kıyaslanmıştır. Ø4 için nümerik analizden elde maksimum teğetsel gerilme $831 \mathrm{MPa}$ iken, analitik hesaplamalarda 774,8 MPa, Ø6 için nümerik analizde $587 \mathrm{MPa}$ iken analitik hesaplamalarda 619,8 MPa, Ø10 için nümerik analizde $495 \mathrm{MPa}$ iken analitik hesaplamalarda 369,9 MPa'dır. Elde edilen sonuçların birbirine oldukça yakın olduğu görülmektedir. Elde edilen değerler arasındaki fark için, literatürdeki sayısal analizlerin daha güvenilir sonuçlar doğurduğu göz önünde bulundurularak, nümerik analizle daha hassas hesap yapıldığg söylenebilir. 


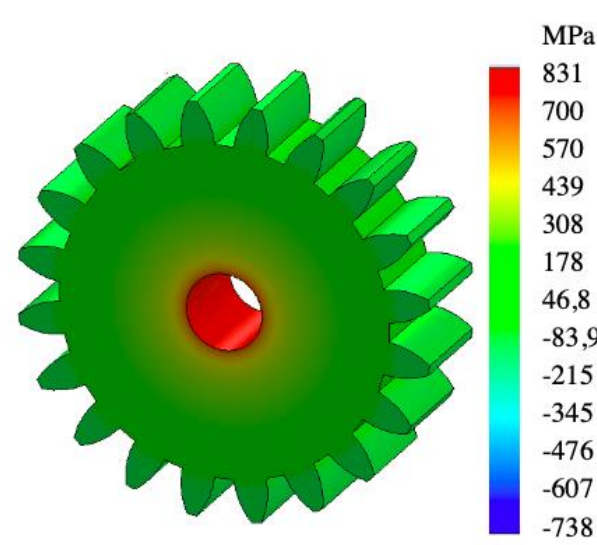

a. $\varnothing 4 \mathrm{H} 7 / \mathrm{u} 6$

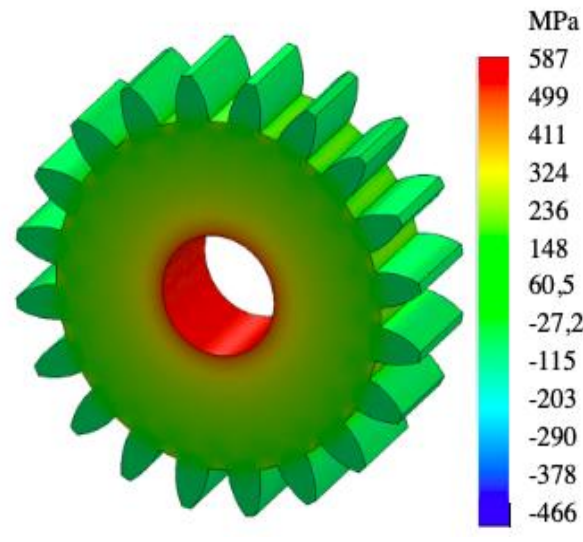

b. Ø6 H7/u6

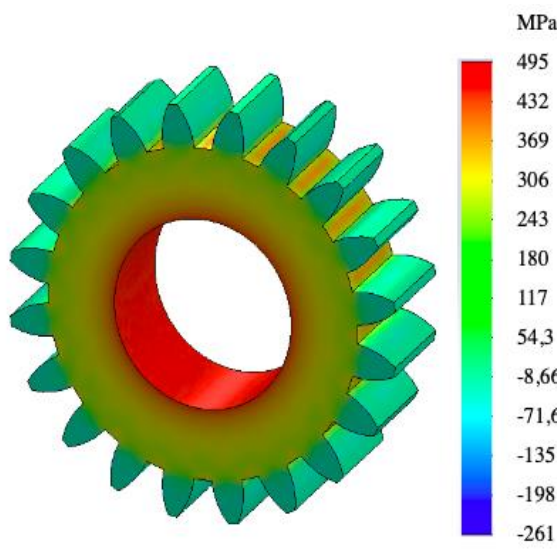

c. Ø10 H7/u6

Şekil 3. H7/u6 mil göbek bağlantısında nominal çapın teğetsel gerilmeye etkisi

Ø5 için oluşturulan sıkı geçme bağlantılarının nümerik analizlerinden elde edilen radyal gerilme sonuçları Şekil 4 'te yer almaktadır. En büyük radyal gerilme $\varnothing 5$ H7/u6 sıkı geçme bağlantısında meydana gelmiş olup -583 MPa'dır. Bunu sırasıyla -508 MPa radyal gerilme ile Ø5 H7/s6 ve -378 MPa radyal gerilme ile Ø5 H7/p6 takip etmektedir. Elde edilen bu verilerin, Şekil 1'deki sonuçlara oldukça yakın olduğu görülmektedir. Nümerik ve analitik olarak elde edilen teğetsel gerilme sonuçlarına benzer şekilde sıklık arttıkça mil göbek bağlantısında oluşan radyal gerilme artmaktadır.

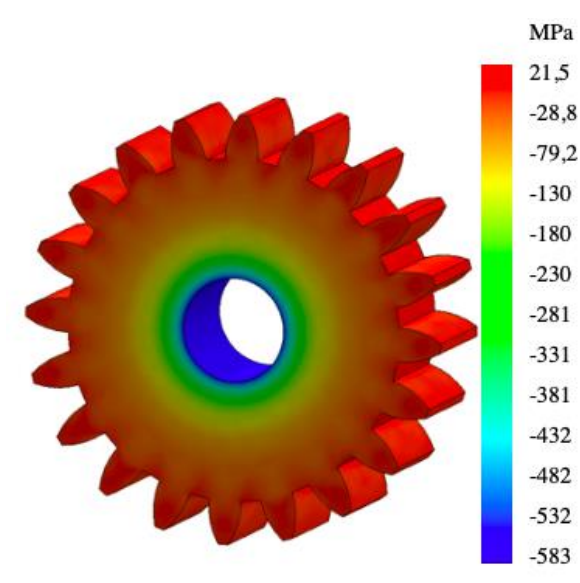

a. $\varnothing 5 \mathrm{H} 7 / \mathrm{u} 6$

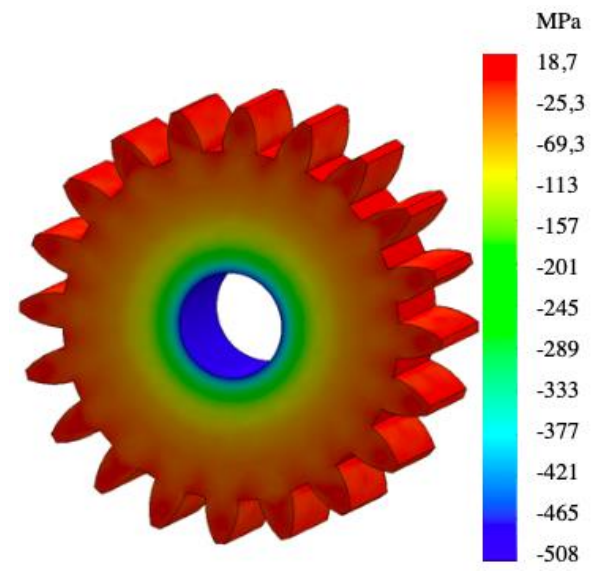

b. $\varnothing 5 \mathrm{H} 7 / \mathrm{s} 6$

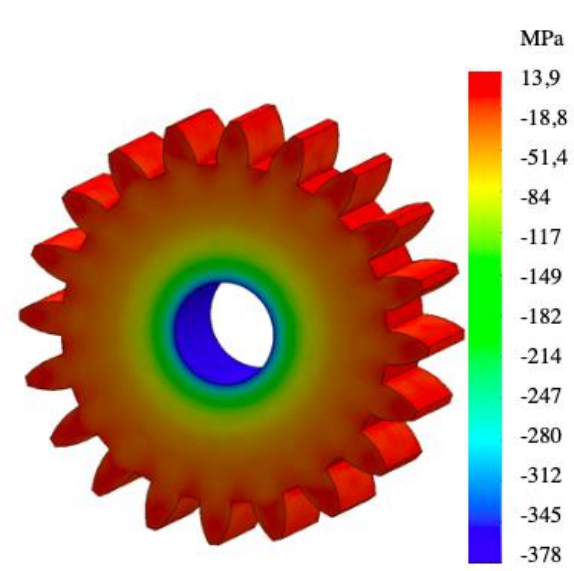

c. $\varnothing 5 \mathrm{H} 7 / \mathrm{p} 6$

Şekil 4. Ø5 sıkı geçme bağlantılarında oluşan radyal gerilme

H7/u6 mil göbek bağlantısında en büyük radyal gerilme oluştuğundan nominal çapın dişlide meydana gelen radyal gerilmeye etkisi Şekil 5 yardımıyla incelenmiştir. Mil göbek bağlantısında meydana gelen radyal gerilme nominal çap arttıkça azalmaktadır. Ayrıca diş gövdesi ve dişler arasındaki gerilme dağılmı özellikle $\varnothing 10$ göbeğe sahip dişlide farklılık göstermiştir. Bu noktada, dişlinin tüm gövdesinde her ne kadar daha az gerilme oluşsa da tasarım esnasında zayıf dişli gövdesinin herhangi bir hasar görmemesi için gerekli kontroller yapılmalıdır.

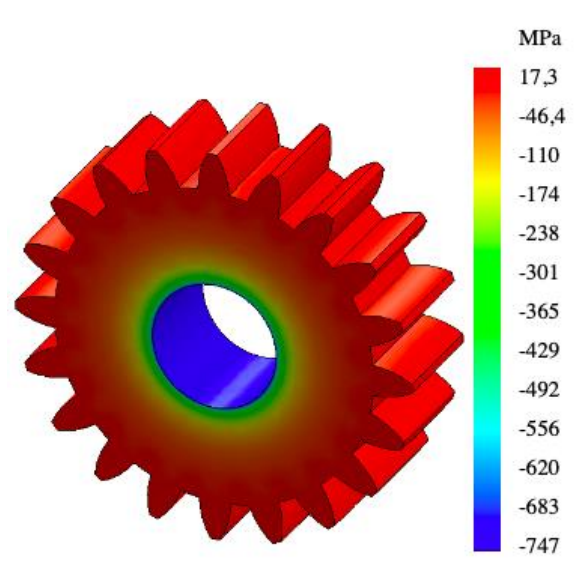

a. Ø4 H7/u6

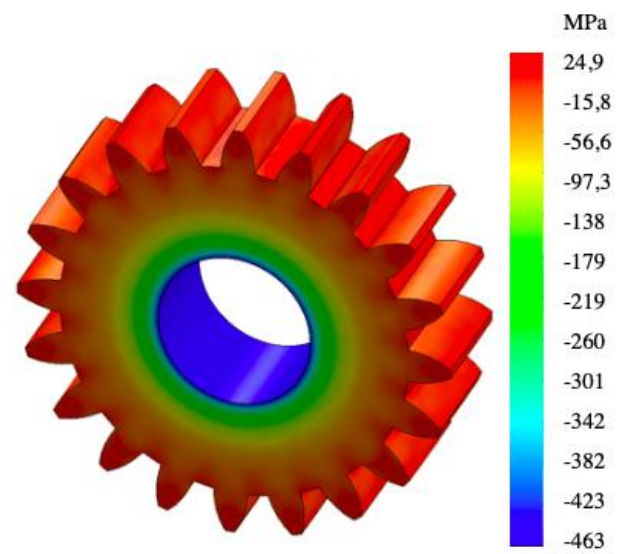

b. Ø6 H7/u6

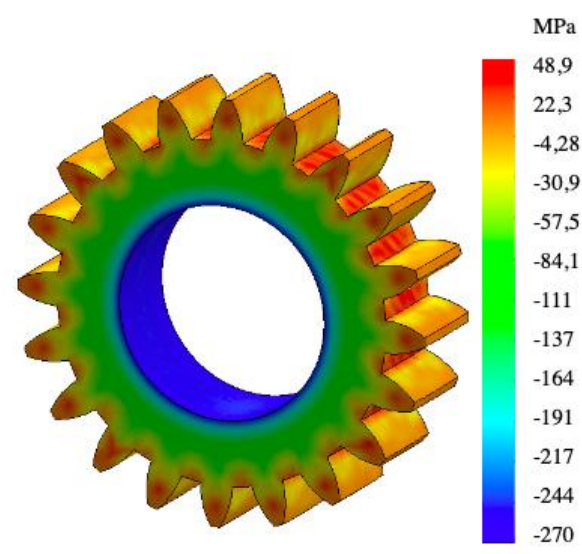

c. $\varnothing 10 \mathrm{H} 7 / \mathrm{u} 6$

Şekil 5. H7/u6 mil göbek bağlantısında nominal çapın radyalgerilmeye etkisi 


\section{Sonuç}

Sıkı geçme bağlantılarında, silindirik iki parça arasındaki sürtünmeden faydalanılarak bağlantı sağlanır. Sıkı geçme bağlantılarından biri de dişli-mil sıkı geçme bağlantılarıdır. Bu tip bağlantıların en önemli avantajı ucuz olmasının yanı sıra dişlinin merkezlenmesindeki kolaylıktır. Burada, tasarımcının dikkat etmesi gereken husus dişli göbeğinin yüksek basınca dayanabilme kabiliyetidir. Bunun için her ne kadar dişli göbeğinin geniş olması gerekse de geniş olmadığı durumlarda da emniyetli tasarımlar ile bu durumun üstesinden gelinebilir.

Bu çalışmada farklı göbek çaplarına sahip 1 mm modül, 6 mm genişlik ve 20 diş sayısına sahip bir mikro modül dişlinin; farklı sıkı geçme toleranslarında oluşan gerilme dağılımları sayısal ve analitik olarak hesaplanarak karşılaştırmalı olarak incelenmiştir. Nominal çap arttıkça teğetsel ve radyal gerilmenin azaldığı görülmüştür. Ancak, dişli mil sıkı bağlantılarının dezavantajlarından dişli yüzey alanındaki azalmanın emniyeti tasarım için göz önünde bulundurulmalıdır. Çalışmada kullanılan tüm nominal çap değerleri için teğetsel gerilme büyükten küçüğe doğru H7/u6, H7/s6, H7/p6 şeklinde siralanmaktadır. Elde edilen analitik ve nümerik sonuçlar birbirini destekler niteliktedir. Çalışmanın özellikle küçük boyutlu çeşitli dişli-mil bağlantıları için tekrarlanması faydalı olacaktır.

\section{Kaynakça}

[1] Wittel, H., Muhs D., Jannasch, D., Joachim V. (2013). Roloff/Matek maschinenelemente. Springer, Augsburg, Almanya

[2] Kovan, V. (2018). Elasto-Plastic Separation Frequency Analysis of Interference Fitted Joints in Lightweight Materials. International Journal of Computational Methods, 15 (4), 1-15.

[3] Kovan V. (2011). Separation frequency analysis of interference fitted hollow shaft-hub connections by finite element method. Advances in Engineering Software, 42, 644-648.

[4] Xiang, D., Shen, G., Zhu, K., Shen, Y., Jiang, L. (2017). Interference contact characteristics of planetary gear train for wind turbines. Journal of Vibration and Shock, 36 (5), 17-22.

[5] Pedersen, N.L. (2016). On optimization of interference fit assembly. Structural and Multidisciplinary Optimization, 54 (2), 349 359.

[6] Zhou, Y., Ding, L., Niu, P.H., Li, D.L. (2018). Study on the Machining Process of Circular Arc Gear with Interference Fit. Transaction of Beijing Institute of Technology, 38 (11), 1120-1125.

[7] Zhao, J., Lin, T.J., Zhong, S., Song, J.J. (2016). Fatigue Life and its Influence Factor Analysis of Interference Fit Position of Planetary Gear and Bearing. Journal of Dalian University of Technology, 56 (4), 355-361.

[8] Joshi, Y.V. (2018). Gear Interference-Fit Joint Considerations and Design for the Resultant Tooth Distortion. SAE Technical Papers, April.

[9] Boutoutaou, H., Fontaine, J.F. (2015). Methodology for a Computer-Aided Design of Shrink Fits that Considers the Roughness and Form Defects of the Manufacturing Process. Journal of Mechanical Science and Technology, 29 (5), 2097-2103.

[10] Croccolo, D., De Agostinis, M. and Vincenzi, N. [2011] "How to Improve Static and Fatigue Strength in Press-Fitted Joints Using Anaerobic Adhesive,” P. I. Mech. Eng. C-J. Mec.225, 2792-2803.

[11] Kim, S. S. and Lee, D. G. (2006). Design of the Hybrid Composite Journal Bearing Assembled by İnterference Fit. Composite Structures, 75, 222-230.

[12] Lewis, R., Marshall, M. B. and Dwyer-Joyce, R. S. (2005). Measurement of Interface Pressure in Interference Fits. Proceedings of The Institution of Mechanical Engineers Part C-Journal of Mechanical Engineering Science, 219, 127-139.

[13] Lame, G. and Clapeyron, B. (1831). Memoire sur l' equilibre interieur des corps solides homogeenes. Journal für die reine und angewandte Mathematik, 7, 391-423.

[14] Eyercioglu, O., Kutuk, M. A. and Yilmaz, N. F. (2009). Shrink Fit Design for Precision Gear Forging Dies. Journal of Materials Processing Technology, 209, 2186-2194.

[15] Zhang, Y., McClain, B. and Fang, X. D. (2000). Design of Interference Fits via Finite Element Method. International Journal of Mechanical Sciences, 42, 1835-185.

[16] Chakherlou, T. N. and Abazadeh, B. (2012). Experimental and Numerical Investigations about the Combined Effect of Interference Fit and Bolt Clamping on the Fatigue Behavior of Al 2024-T3 Double Shear Lap Joints. Materials \& Design, 33, $425-435$.

[17] Chakherlou, T. N., Mirzajanzadeh, M. and Saeedi, K. H. (2010). Fatigue Crack Growth and Life Prediction of a Single Interference Fitted Holed Plate. Fatigue \& Fracture of Engineering Materials \& Structures, 33, 633-644.

[18] Sniezek, L., Zimmerman, J. and Zimmerman, A. (2010). The Carrying Capacity of Conical Interference-Fit Joints with Laser Reinforcement Zones," Journal of Materials Processing Technology, 210, 914-925.

[19] Lanoue, F., Vadean, A. and Sanschagrin, B. (2009). Finite Element Analysis and Contact Modelling Considerations of Interference Fits for Fretting Fatigue Strength Calculations. Simulation Modelling Practice and Theory, 17, 1587-1602.

[20] Sun, M. Y., Lu, S. P., Li, D. Z., Li, Y. Y., Lang, X. G. and Wang, S. Q. (2010). Three-dimensional Finite Element Method Simulation and Optimization of Shrink Fitting Process for a Large Marine Crankshaft," Materials \& Design, 31, $4155-4164$.

[21] Yang, G. M., Coquille, J. C., Fontaine, J. F. and Lambertin, M. (2001). Influence of roughness on characteristics of tight interference fit of a shaft and a hub. International Journal of Solids and Structures, 38, 7691-7701.

[22] Mucha, J. (2009). Finite Element Modeling and Simulating of Thermomechanic Stress in Thermocompression Bondings. Materials \& Design, 30, 1174-1182.

[23] ASME B4.2-1978, Preferred Metric Limits and Fits. (2009) ASME International, New York.

[24] Timoshenko, S. (1947). Strength of materials, part II - Advanced Theory and Problems, D. Lancaster: Van Nostrand Company

[25] Budynas, R. G., Nisbett, J. K., Shigley, J. E. (2011). Shigley's mechanical engineering design. New York: McGraw-Hill. 